\title{
Can a Simple Geriatric Assessment Predict the Outcome of TURP?
}

\author{
Klaus Eredics ${ }^{a}$ Christine Meyer ${ }^{b}$ Tanja Gschliesser ${ }^{c}$ Branimir Lodeta ${ }^{c}$ \\ Ortwin Heissler $^{d}$ Thomas Kunit ${ }^{\mathrm{e}}$ Stephan Madersbacher ${ }^{b, f}$ \\ ${ }^{a}$ Department of Urology, Donauspital, Vienna, Austria; ${ }^{b}$ Department of Urology, Kaiser Franz Josef Hospital, Vienna, \\ Austria; ' Department of Urology, Klinikum Klagenfurt, Vienna, Austria; ${ }^{\mathrm{d}}$ Department of Urology, Landesklinikum

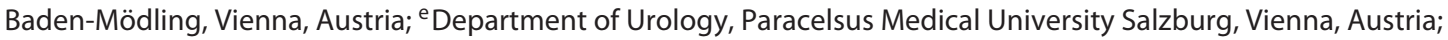 \\ fDepartment of Urology, Sigmund Freud Private University, Vienna, Austria
}

\section{Keywords}

TURP · Geriatric · Outcome · Geriatric assessment · Benign prostatic hyperplasia $\cdot$ Lower urinary tract symptoms

\begin{abstract}
Purpose: To determine the impact of a simple preoperative geriatric assessment on the outcome in older patients with recurrent urinary retention who underwent desobstructive surgery. Patients and Methods: Patients aged 75 years or older with recurrent urinary retention referred for TURP entered this prospective, multicentre study. Several demographic, intra- and postoperative parameters were assessed. Preoperative geriatric assessment was performed by the 7-item Canadian Study of Health and Ageing (CSHA) frailty scale (1: very fit, 7: severely frail; completion takes less than a minute). The main outcome parameters were successful voiding rates at discharge and 3 months postoperatively. $\boldsymbol{R} \boldsymbol{e}$ sults: A total of 54 patients were recruited; 42 (77.8\%) patients had a CSHA index of 1-3 and were considered as "fit", the remaining 12 (22.2\%) formed the "frail" group (CSHA index 4-7). Age was identical in both cohorts (79.5 \pm 3.7 vs. $79.7 \pm 3.3$ years); differences were demonstrable for the
\end{abstract}

American Society of Anesthesiologists (ASA) score ( $p=$ 0.001 ), the number of daily medications ( $>4: 32$ vs. $75 \%, p=$ 0.02 ), falls within the past 6 months ( 12 vs. $33 \%)$, and the necessity of home/nursing care (5 vs. $42 \%, p=0.004)$. Intra- and perioperative complications, duration of postoperative catheterization, and length of hospitalization were identical in both cohorts. The success rate at discharge was $80.6 \%$ in fit and $75.0 \%$ in frail patients; the respective values at 3 months were 95.2 and $83.3 \%$. Conclusions: A simple 1-min geriatric assessment tool can predict - to a certain extent the outcome of desobstructive surgery in older patients with recurrent urinary retention. Fit patients achieve an excellent outcome while frail patients might benefit from a more indepth urodynamic/geriatric evaluation.

(c) 2020 S. Karger AG, Basel

\section{Introduction}

The ever-increasing older population is one of the major challenges in medicine. Austria (total population: 8.3 million) currently has 414,000 inhabitants aged 80 years or older, and this number will increase to 639,000 in 2030 karger@karger.com

www.karger.com/uin

Karger ${ }^{\prime}=$
(C) 2020 S. Karger AG, Basel

Professor and chairman, Department of Urology

Kaiser Franz Josef Hospital, Kundratstrasse 3

AT-1100 Vienna (Austria)

stephan.madersbacher@wienkav.at 
and to 1.1 million in 2060, indicating a rise of $166 \%$ [1]. These demographic changes will substantially increase the number of older patients requiring surgical intervention for lower urinary tract symptoms in upcoming decades [2].

The indication for desobstructive surgery in older, particularly frail, patients has to balance life expectancy, functional outcome, and surgical risk. Approximately $12 \%$ of patients older than 75 years of age die within 12 months after the first episode of urinary retention, and this rate increases up to $30 \%$ in nursing home patients who underwent TURP [3, 4]. In parallel, the functional outcome decreases with advancing age $[5,6]$. Morbidity after TURP is increased significantly by age, polypharmacy, and preoperative urinary catheterization [7].

While all lower urinary tract symptoms/benign prostatic hyperplasia guidelines delineate the preoperative urological work-up in detail, there are no specific recommendations regarding a geriatric assessment [8]. This is surprising given the fact that TURP is a procedure predominantly in the elderly and is performed in frail, multimorbid patients. The slow inclusion of any geriatric assessment in the routine work prior to surgery in general is due to the complexity of a thorough geriatric assessment and the unclear outcome prediction. Pichon et al. [9] just recently published the first study analysing the impact of a geriatric assessment on the TURP outcome.

The aim of this prospective study was to analyse the role of the Canadian Study of Health and Ageing (CSHA) frailty scale (which is a very simple geriatric assessment tool that takes less than a minute to be completed) in predicting the outcome in older patients with recurrent urinary retention who underwent desobstructive surgery [10].

\section{Patients and Methods}

\section{Study Design}

This prospective, multicentric study evaluated a consecutive series of patients aged 75 years or older, who were referred to desobstructive surgery (TURP) for recurrent urinary retention and at least one unsuccessful trial without catheter under $\alpha$-blocker therapy. All procedures were performed by an experienced urologist with a personal history of $>100$ previous surgeries.

Several demographic parameters were collected such as age, falls within the past 6 months, number of regular oral medications, social support at home, home situation, pain at home, American Society of Anesthesiologists (ASA) score, and body mass index. The following laboratory parameters were also collected at baseline: eGFR, CRP, total protein, haemoglobin, and haematocrit.
Table 1. Patient characteristics

\begin{tabular}{lclll}
\hline & $\begin{array}{l}\text { Total } \\
\text { cohort } \\
(n=54)\end{array}$ & $\begin{array}{l}\text { CSHA } \\
1-3 \\
(n=42)\end{array}$ & $\begin{array}{l}\text { CSHA } \\
4-7 \\
(n=12)\end{array}$ & $\begin{array}{l}p \\
\text { value }\end{array}$ \\
& $79.5 \pm 3.6$ & $79.5 \pm 3.7$ & $79.7 \pm 3.3$ & 0.8 \\
\hline Age, years & & & & \\
ASA & 3.7 & 5 & 0 & \\
$\quad$ I & 40.7 & 56 & 0 & \\
$\quad$ II & 48.1 & 39 & 100 & 0.001 \\
III & 37 & 47 & 0 & \\
Daily medications & 22 & 21 & 25 & \\
$\quad 0-2$ & 39 & 32 & 75 & 0.02 \\
$\quad 3-4$ & 18.5 & 12 & 33 & 0.19 \\
$\quad$ 4 & 12.9 & 5 & 42 & 0.004 \\
Falls in last 6 months & $65 \pm 17$ & $65 \pm 18$ & $64 \pm 17$ & 0.9 \\
Home care & $13.4 \pm 1.9$ & $13.5 \pm 2.0$ & $13.4 \pm 1.6$ & 0.9 \\
eGFR, mL/min/1.7 m $^{2}$ & & & & \\
Hb, g/L & & & & \\
\hline
\end{tabular}

Data are presented as mean $\pm \mathrm{SD}$ or $\%$, as appropriate.

Preoperative urological work-up included assessment of duration of catheterization, prostate volume, and the presence of bladder stone, hydronephrosis, and urine culture. Intraoperative and in-house complications were recorded.

Primary outcome parameters were spontaneous micturition after the first catheter removal and voiding status after hospital discharge. Secondary outcome parameters were duration of catheterization and post-void residual volume. A follow-up examination was performed 3 months after surgery with assessment of voiding status and measurement of residual volume urine by ultrasound.

\section{Geriatric Assessment}

The CSHA clinical frailty scale is a basic and easy to use geriatric assessment that grades patients in 7 categories (1: very fit, 2: fit, 3: well, with treated comorbid disease, 4: apparently vulnerable, 5: mildly frail, 6: moderately frail, 7: severely frail) [10]. This scale is supported by pictograms and a short accompanying text making completion feasible within less than a minute [10].

CSHA data collection was performed by the ward physicians or urologists on the day of admission, and patients with a CSHA index of 1-3 were classified as "fit," whereas patients with an CSHA index of 4-7 were graded as "frail."

\section{Statistical Analyses}

All data are presented as mean and standard deviation. All analyses were obtained using IBM IPSS Statistics for Windows v20.0. The $\chi^{2}$ test and Student's $t$ test were used to analyse differences between baseline and outcome parameters. A $p$ value of $<0.05$ was considered significant. 
Table 2. Surgical data

\begin{tabular}{|c|c|c|c|c|}
\hline & $\begin{array}{l}\text { Total cohort } \\
(n=54)\end{array}$ & $\begin{array}{l}\text { CSHA } 1-3 \\
(n=42)\end{array}$ & $\begin{array}{l}\text { CSHA } 4-7 \\
(n=12)\end{array}$ & $p$ value \\
\hline Prostate volume, $\mathrm{mL}$ & $66 \pm 33$ & $70 \pm 36$ & $52 \pm 20$ & 0.04 \\
\hline Residual volume, $\mathrm{mL}$ & $87 \pm 158$ & $83 \pm 152$ & $98 \pm 128$ & 0.8 \\
\hline \multicolumn{5}{|l|}{ Preop catherization } \\
\hline$<1$ month & 15 & 14 & 17 & \\
\hline 1-2 months & 43 & 45 & 33 & \\
\hline 3-5 months & 29 & 31 & 25 & \\
\hline$>5$ months & 13 & 10 & 25 & \\
\hline Positive urine culture & 79 & 100 & 0.2 & \\
\hline Duration of surgery, min & $66 \pm 33$ & $71 \pm 32$ & $50.5 \pm 31$ & 0.06 \\
\hline Resected volume, $\mathrm{g}$ & $38 \pm 31$ & $39 \pm 34$ & $30 \pm 17$ & 0.17 \\
\hline Postop catheterization, days & $3.7 \pm 2.8$ & $3.8 \pm 3.0$ & $3.2 \pm 1.0$ & 0.8 \\
\hline Hospitalization, days & $6.6 \pm 2.3$ & $6.4 \pm 2.1$ & $7.1 \pm 3.1$ & 0.4 \\
\hline
\end{tabular}

Data are presented as mean $\pm \mathrm{SD}$ or $\%$, as appropriate.

Table 3. In-house complications and outcome at 3 months

\begin{tabular}{|c|c|c|c|c|}
\hline & $\begin{array}{l}\text { Total cohort } \\
(n=54)\end{array}$ & $\begin{array}{l}\text { CSHA } 1-3 \\
(n=42)\end{array}$ & $\begin{array}{l}\text { CSHA } 4-7 \\
(n=12)\end{array}$ & $p$ value \\
\hline \multicolumn{5}{|l|}{ Complications } \\
\hline Blood transfusion ${ }^{a}$ & $3(5.6)$ & $3(7.1)$ & 0 & 0.6 \\
\hline Re-intervention w/o anaesthesia ${ }^{b}$ & $2(3.7)$ & $2(4.8)$ & 0 & 0.6 \\
\hline Re-intervention with anaesthesia ${ }^{c}$ & $1(1.9)$ & $1(2.4)$ & 0 & 0.7 \\
\hline Febrile UTI & $1(1.9)$ & $1(2.4)$ & 0 & 0.8 \\
\hline \multicolumn{5}{|l|}{ Outcome } \\
\hline Catheter free at discharge & $43(79.6)$ & $34(80.6$ & $9(75.0)$ & 0.34 \\
\hline Catheter free at 3 months & $50(92.6)$ & $40(95.2)$ & $10(83.3)$ & 0.21 \\
\hline Post-void residual volume, $\mathrm{mL}$ & $28 \pm 38$ & $26 \pm 40$ & $32 \pm 33$ & 0.4 \\
\hline
\end{tabular}

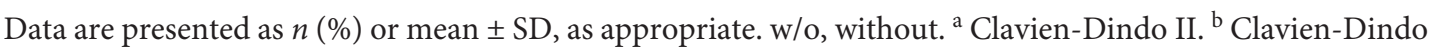
IIIa. ${ }^{\mathrm{c}}$ Clavien-Dindo IIIb.

\section{Results}

\section{Patient Characteristics}

The demographic data presented in Table 1 demonstrate (i) a high degree and (ii) a significant heterogeneity of co-morbidities in older men (75+) referred for TURP for recurrent urinary retention. In this cohort $(n=54)$, falls within the past 6 months were reported by $18.5 \%$, $39 \%$ took more than 4 drugs on a regular basis, and an ASA 3 score was present in $48.1 \%$.

The frequency distribution of the CSHA index was as follows: $1: n=12,2: n=16,3: n=15,4: n=6,5: n=4,6$ : $n=2$, and $7: n=0$. Forty-two (78\%) patients had a CSHA

Can a Simple Geriatric Assessment

Predict the Outcome of TURP? index of 1-3 and formed the fit cohort, the remaining 12 with a CSHA index 4-6 were considered frail, and no patient was classified as CSHA 7. The frail cohort had a higher ASA score $(p=0.001)$, a higher rate of daily medication $(p=0.02)$, and a higher rate of nursing care $(p=$ 0.02 ) (Table 1). In this cohort, there was also a numerically higher rate of falls within the past 6 months (33 vs. $12 \%)$. Chronological age was identical in both cohorts (Table 1).

\section{Urological Parameters}

Mean prostate volume was $66 \mathrm{~mL}, 42.5 \%$ had the catheter preoperatively for longer than 2 months, and bladder 
trabeculation was present in $86 \%$. Apart from prostate volume, which was larger in the fit cohort (70 \pm 36 vs. $52 \pm 20 \mathrm{~mL}, p=0.04$ ), there was no significant difference in any preoperative parameter, such as prostate volume, rate of positive urine culture, and duration of catheterization between the fit and frail cohorts (see Table 1).

\section{Surgical Data and In-House Complications}

The duration of surgery was longer in the fit cohort (71 vs. $51 \mathrm{~min}, p=0.06$ ), reflecting prostate size differences (Table 2). Resection efficacy (portal vein/resected volume) was in the range of 55\% in both cohorts (Table 2). Postoperative catheterization was slightly longer in the fit cohort (3.8 vs. 3.2 days, not significant). The length of hospitalization ( 6.4 vs. 7.1 days) has to be interpreted in the context of age, co-morbidities, and the public health care system in Austria, as there is no incentive to discharge patients early. Surgery was safe: the overall transfusion rate was $5.6 \%$ and only 1 patient $(1.9 \%)$ required a re-intervention with anaesthesia for clot retention/coagulation (Table 3).

\section{Outcome at 3 Months}

TURP is an efficient procedure, which was also proven in this cohort. At discharge $79.6 \%$ of patients were catheter free and this percentage increased to $92.6 \%$ at 3 months. Success rates at both time points were higher in fit patients: 80.9 vs. $75 \%$ and 95.2 vs. $83.3 \%$, respectively (Table 3). Post-void residual volume at 3 months was less than $50 \mathrm{~mL}$ in both cohorts (Table 3 ).

\section{Discussion}

This prospective, multicentre centre study demonstrates (i) a significant heterogeneity regarding co-morbidities/physical status in older (75+) patients referred for desobstructive surgery due to recurrent urinary retention and (ii) that a simple geriatric assessment can predict - to a certain degree - the 3-month success rate. In the fit cohort ( $78 \%$ of all patients), the success rate was $95 \%$, and this percentage dropped to $83 \%$ in the frail cohort. The major limitation of this study is the sample size (particularly of the frail cohort) and that urodynamic testing was not included to the preoperative urological work-up. An additional limitation is the rather short follow-up time of 3 months; but given the limited life expectancy of this geriatric population, this duration was considered to provide valid information.
Several studies have documented the safety and efficacy of desobstructive surgery (mainly TURP) also in the elderly, although complication and success rates are less favourable [5-7]. In a large-scale Bavarian study, Reich et al. [7] reported on the outcome of 10,654 patients following TURP; in those with retention a successful catheter withdrawal was reported in $88 \%$. Studies focussing on older men ( $>75-80$ years) reported on a successful catheter withdrawal in the range of $65-89 \%$; our figure of $79 \%$ fits in this range $[5,6]$. Three months after surgery, $92 \%$ of all patients were catheter free in our series. Others, however, have reported on disappointing outcomes of desobstructive surgery in frail patients. Suskind et al. [4] studied 2,869 nursing home patients who underwent desobstructive surgery. The outcome for patients with preoperative catheterization ( $n=1,178$; age 80.6 years; Charlson comorbidity scale $\geq 2: 45.5 \%$ ) at 12 months was as follows: $30 \%$ have died and of those alive, $95 \%$ were again on permanent catheterization (the indication for re-catheterization was not stated) [4]. These data underline the urgent need for a better preoperative work-up/ classification in older, frail patients.

Numerous geriatric assessment tools covering various aspects of ageing have been developed [11]. The slow adoption of geriatric assessments is partly due to the complexity of the proposed tools and the unclear prediction regarding outcome [11]. The major benefit of the CSHA frailty index is its simplicity, as it takes less than a minute to be completed $[10,11]$. That is why we choose this tool for the current investigation.

According to our knowledge, there is only one study available that has investigated the impact of a preoperative geriatric assessment on the outcome after TURP [9]. This study served as a stimulus for the current one and we chose an identical study cohort (age 75+ years, recurrent urinary retention). This paucity of data is all the more surprising given the high prevalence and heterogeneity of comorbidities and physical status in older patients referred for desobstructive surgery [9]. This is also shown by the frequency distribution of the CSHA score in our cohort.

Pichon et al. [9] have prospectively analysed 60 men older than 75 years with an indwelling catheter who received desobstructive surgery (mainly TURP). Patients underwent a brief and a more comprehensive geriatric assessment to classify them into "vigorous," and "vulnerable." Success was defined by the bladder catheter withdrawal after surgery. After geriatric assessment, 33 patients were classified as the vigorous group (55\%), and 25 as vulnerable. The success rate at 3 months after surgery was 94 and 55\%, respectively $(p<0.05)$. The morbidity 
was higher for the vulnerable group. The authors concluded that a geriatric assessment can predict the outcome of endoscopic benign prostatic hyperplasia surgery for patients in retention older than 75 years.

The series of Pichon et al. [9] and our study can provide some recommendations for the management of older patients with retention subjected for desobstructive surgery. Both series reported on almost identical, high success rates at 3 months in fit patients (94\%/95\%). This value is comparable to younger men. There is no doubt that fit older patients with recurrent urinary retention profit from desobstructive surgery, and surgery should be generously offered, irrespective of chronological age. The second major finding of both studies was that frail patients have a worse outcome, albeit the difference in the series of Pichon et al. [9] was considerable higher than in ours (55 vs. $83 \%$ ). The reason for this difference in discriminatory power remains speculative and could be due to patient selection, case mix, indication for surgery, or sample size, but also differences in the geriatric assessment. The lower success rate of TURP in frail patients paralleled by higher anaesthesiologic and complication risks in most series underline the role of less invasive procedures such as Rezum, UroLift, or prostate embolization in this cohort [12-14]. Although none of the studies with these procedures have applied a systematic geriatric assessment, the failure rates reported in patients "unfit for surgery" are not dissimilar to those after TURP in frail patients.

The pathomechanisms responsible for the association between geriatric status and the outcome of TURP remains to be elucidated. It is well known that the prevalence of detrusor underactivity increases with age, contrasted by a decline of bladder outflow obstruction [15, 16]. Although detrusor underactivity is linked with axonal degeneration, muscle loss, fibrosis, and associated neurologic disease, it is not known whether there is an association with the geriatric status $[15,16]$. Further- more, the impact of urodynamic findings, such as detrusor underactivity, on the outcome of desobstructive surgery is still controversially discussed $[17,18]$.

\section{Conclusions}

A simple 1-min geriatric assessment can discriminate the outcome of desobstructive surgery in older men with retention. The fit cohort (78\% in our series) should be offered surgery as they achieve a success rate in the range of $95 \%$. Frail patients may benefit from a more in-depth urodynamic and geriatric evaluation and should be offered less invasive procedures.

\section{Statement of Ethics}

The study received approval from the local ethics committee. Informed consent was obtained from all individual participants included in this study.

\section{Disclosure Statement}

All authors declare that they have no conflict of interest.

\section{Funding Sources}

The authors have no funding sources to disclose.

\section{Author Contributions}

Klaus Eredics: protocol development, data collection, data analysis, and manuscript writing. Christine Meyer, Tanja Gschliesser, Branimir Lodeta, Ortwin Heissler, and Thomas Kunit: data collection. Stephan Madersbacher: protocol development and manuscript editing.

\section{References}

Can a Simple Geriatric Assessment

Predict the Outcome of TURP?
1 Statistik Austria. Available from: www.statistik.at.

2 Lim KB. Epidemiology of clinical benign prostatic hyperplasia. Asian J Urol. 2017 Jul; 4(3):148-51.

3 Armitage JN, Sibanda N, Cathcart PJ, Emberton M, van der Meulen JH. Mortality in men admitted to hospital with acute urinary retention: database analysis. BMJ. 2007 Dec; 335(7631):1199-202.

4 Suskind AM, Walter LC, Zhao S, Finlayson E. Functional outcome after transurethral resection of the prostate in nursing home residents. J Am Geriatr Soc. 2017 Apr;65(4):699-703.
5 Brierly RD, Mostafid AH, Kontothanassis D, Thomas PJ, Fletcher MS, Harrison NW. Is transurethral resection of the prostate safe and effective in the over 80-year-old? Ann R Coll Surg Engl. 2001 Jan;83(1):50-3.

6 Mebust WK, Holtgrewe HL, Cockett AT, Peters PC. Transurethral prostatectomy: immediate and postoperative complications. A cooperative study of 13 participating institutions evaluating 3,885 patients. J Urol. 1989 Feb;141(2):243-7. 
7 Reich O, Gratzke C, Bachmann A, Seitz M, Schlenker B, Hermanek P, et al.; Urology Section of the Bavarian Working Group for Quality Assurance. Morbidity, mortality and early outcome of transurethral resection of the prostate: a prospective multicenter evaluation of 10,654 patients. J Urol. 2008 Jul; 180(1):246-9.

8 Gravas S, Cornu JN, Gacci M, et al. Management of non-neurogenic male LUTS. www. uroweb.org/guidelines/treatment-of-nonneurogenic-male-luts/ 2019.

9 Pichon T, Lebdai S, Launay CP, Collet N, Chautard D, Cerruti A, et al. Geriatric assessment can predict outcomes of endoscopic surgery for benign prostatic hyperplasia in elderly patients. J Endourol. 2017 Nov;31(11): 1195-202.

10 Rockwood K, Song X, MacKnight C, Bergman H, Hogan DB, McDowell I, et al. A glob- al clinical measure of fitness and frailty in elderly people. CMAJ. 2005 Aug;173(5):48995.

11 Kahlmeyer A, Goebell PJ, Wullich B. [Presurgical assessments]. Urologe A. 2019 Apr; 58(4):373-80. German.

12 Westwood J, Geraghty R, Jones P, Rai BP, Somani BK. Rezum: a new transurethral water vapour therapy for benign prostatic hyperplasia. Ther Adv Urol. 2018 Aug;10(11):32733.

13 Magistro G, Stief CG, Woo HH. Mini-review: what is new in Urolift? Eur Urol Focus. 2018 Jan;4(1):36-9.

14 Malling B, Lönn L, Jensen RJ et al. Prostate artery embolization for lower urinary tract symptoms in men unfit for surgery. Diagnostics (Basel). 2019;9(2). pii:46.

15 Aldamanhori R, Chapple CR. Underactive bladder, detrusor underactivity, definition, symptoms, epidemiology, etiopathogenesis, and risk factors. Curr Opin Urol. 2017 May; 27(3):293-9.

16 Jeong SJ, Kim HJ, Lee YJ, Lee JK, Lee BK, Choo YM, et al. Prevalence and clinical features of detrusor underactivity among elderly with lower urinary tract symptoms: a comparison between men and women. Korean J Urol. 2012 May;53(5):342-8.

17 Welk B, McGarry P, Baverstock R, Carlson $\mathrm{K}$, Hickling $\mathrm{D}$. Do urodynamic findings other than outlet obstruction influence the decision to perform a transurethral resection of prostate? Urology. 2018 Jul;117:120-

18 Lee KH, Kuo HC. Recovery of voiding efficiency and bladder function in male patients with non-neurogenic detrusor underactivity after transurethral bladder outlet surgery. Urology. 2019 Jan;123:235-41. 